\title{
THE BLOOD VOLUME IN HYPERTHYROIDISM
}

\author{
By HSIAO-CHIEN CHANG \\ (From the Department of Medicine, Peiping Union Medical College, Peiping, China)
}

(Received for publication May 4, 1931)

Thyrotoxicosis is almost invariably associated with a certain degree of cardiovascular disturbance. Tachycardia is always one of the first signs of this malady. Demonstrable enlargement of the heart frequently follows. Cardiac arrhythmia, especially auricular fibrillation, and congestive heart failure of ten constitute the important part of the clinical picture during the later part of the course of the disease. Occasionally the patient's death may be directly attributable to cardiac insufficiency. Although various views have been put forward, the cause and nature of these circulatory derangements remain incompletely understood. Attempts to find characteristic histological changes in the myocardium have been without success. The isolated reports of damage to the heart muscle (1) (2) (3) (4) give no convincing evidence that the lesion was specific. That the thyroid heart is not a permanent condition has been recently emphasized by Thomas (5). One of the patients reported by this author died from heart failure, but presented no significant myocardial damage on postmortem examination. On the other hand investigations into the physiological pathology, of the disease have been less disappointing. Years ago Plesch (6) demonstrated an increased minute volume in the patients suffering from exophthalmic goiter. Stewart (7) by his special technic found in Graves' disease an exceptionally large blood flow in the hands and this he thought was in agreement with the flushing of the skin which is commonly seen. More recently the cardiac output in hyperthyroidism has aroused a renewed interest (8) (9) (10) (11) (12). In spite of the widely different methods employed, all investigators with the single exception of Rabinowitch and Bazin (9) have come to the same conclusion as that reached by Plesch. Blumgart, Gargill and Gilligan (13) studied 13 thyrotoxic patients and showed that the 
speed of blood flow through the lungs was much faster than the average normal speed of flow. The velocity of the venous blood flow from the arm to the heart was likewise greatly enhanced. It would thus seem that the cardiac disturbance in thyroid disease may merely represent the effect of prolonged overloading and fatigue of the heart muscle. Inasmuch as the total circulating mass plays an important rôle in hemodynamics an inquiry into this factor should assist greatly in understanding the magnitude of the extra load imposed upon the heart. Blotner, Fitz, and Murphy (14) have already studied the total blood count in this disease. The present communication deals with the blood volume findings in hyperthyroidism and their subsequent changes after partial thyroidectomy.

\section{EXPERIMENTAL}

The blood volume was determined by the carbon monoxide method according to the technic reported previously (15). This is a simple and reliable method with a maximal error of less than 5 per cent. It has the special merit of giving constant and consistent results in the same individual with repeated measurements, thus obviating the objection of an "immunity" effect inherent in the use of dye as pointed out by Lindhard (16). Four normal subjects were observed repeatedly under identical conditions as regards position, environmental temperature, physical activity, and the state of alimentation. Their blood volumes determined by the carbon monoxide method remained practically the same on these different occasions (Table 1).

The routine procedure in the study of the patients was as follows. In measuring the blood volume basal condition was not maintained, but the technic was carefully standardized so that all determinations were done in the afternoon about three hours after lunch, with the patient in recumbent posture, and after thirty minutes of complete rest. The basal metabolic rate was obtained by the Tissot method. The hematocrit readings, red blood cell count and estimation of the oxygen capacity were carried out by the usual methods. In selecting the patients for investigation only frank cases of hyperthyroidism were included. Border line cases and patients with proved organic heart disease were not included.

In all, 21 subjects were studied. The basal metabolic rate ranged 
TABLE 1

Blood volumes of 4 normal subjects on repeated measurements ( $C O$ method)

\begin{tabular}{|c|c|c|c|c|c|c|}
\hline \multirow{2}{*}{ Subject } & \multirow{2}{*}{ Date } & \multirow{2}{*}{ Weight } & \multirow{2}{*}{ Surface area } & \multicolumn{3}{|c|}{ Blood volume } \\
\hline & & & & Total & $\begin{array}{c}\text { Per } \\
\text { kilogram }\end{array}$ & $\begin{array}{l}\text { Per square } \\
\text { meter }\end{array}$ \\
\hline \multirow[t]{4}{*}{ H. C. C. } & September 8, 1928 & $\begin{array}{l}\mathrm{kgm} . \\
64.0\end{array}$ & $\begin{array}{c}\text { square meter } \\
1.75\end{array}$ & $\begin{array}{c}c c . \\
4230\end{array}$ & $\begin{array}{c}c c . \\
66.1\end{array}$ & $\begin{array}{c}c c . \\
2418\end{array}$ \\
\hline & November 5, 1928 & 64.6 & 1.76 & 4170 & 64.5 & 2370 \\
\hline & December 5, 1928 & 64.6 & 1.76 & 4185 & 64.7 & 2370 \\
\hline & February 10, 1929 & 65.0 & 1.77 & 4220 & 65.0 & 2384 \\
\hline \multirow[t]{2}{*}{ C. T. H. } & April 24, 1928 & 65.8 & 1.79 & 4590 & 69.8 & 2565 \\
\hline & June 31,1928 & 64.9 & 1.78 & 4550 & 70.1 & 2557 \\
\hline \multirow[t]{2}{*}{ S. H. L. } & March 13,1928 & 69.7 & 1.87 & 4670 & 67.0 & 2500 \\
\hline & July 26,1928 & 68.0 & 1.86 & 4690 & 69.0 & 2520 \\
\hline \multirow[t]{2}{*}{ S. M. L. } & April 13, 1928 & 52.6 & 1.59 & 3690 & 70.2 & 2320 \\
\hline & August 22, 1928 & 52.0 & 1.58 & 3640 & 70.0 & 2300 \\
\hline
\end{tabular}

between plus 23 and plus 109 per cent. All the subjects had clinical signs of exophthalmic goiter except one patient with a toxic adenoma. The data are summarized in Table 2. The average blood volume was $77.8 \mathrm{cc}$. per kilogram of body weight and $2624 \mathrm{cc}$. per square meter of body surface, both being definitely higher than the respective normal values. $^{1}$ In more than half of the patients the blood volume was higher than the maximal limit obtained in the normal series reported elsewhere (15). However, no definite correlation can be shown to exist between the extent of the increase in blood volume and the height of the basal metabolism. This is not surprising in view of the individual variation of both of these physiological factors in the normal subjects. The red blood cell count and the oxygen capacity seemed to fall within normal limits, except in Case 12 in which there was a definite reduction in hemoglobin. This is consistent with the belief that anemia is probably a rare event in uncomplicated hyperthyroidism (17). In no case was any appreciable polycythemia encountered.

1 The blood volume of 16 normal adults determined by the same method averaged $66.6 \mathrm{cc}$. per kilogram of body weight and $2474 \mathrm{cc}$. per square meter of body surface (15). 
TABLE 2

Blood volume, oxygen capacity, hematocrit reading, red blood cell count and basal metabolism in 21 cases of hyperthyroidism

\begin{tabular}{|c|c|c|c|c|c|c|c|c|}
\hline \multirow{2}{*}{$\begin{array}{c}\text { Case } \\
\text { num- } \\
\text { ber }\end{array}$} & \multirow{2}{*}{ Sex } & \multirow{2}{*}{$\begin{array}{c}\text { Basal } \\
\text { metabolic } \\
\text { rate }\end{array}$} & \multicolumn{3}{|c|}{ Blood volume } & \multirow{2}{*}{$\begin{array}{l}\text { Red blood } \\
\text { cells }\end{array}$} & \multirow{2}{*}{$\begin{array}{c}\text { Oxygen } \\
\text { capacity }\end{array}$} & \multirow{2}{*}{$\begin{array}{c}\text { Cell } \\
\text { volume }\end{array}$} \\
\hline & & & Total & $\begin{array}{c}\text { Per } \\
\text { kilogram }\end{array}$ & $\begin{array}{c}\text { Per square } \\
\text { meter }\end{array}$ & & & \\
\hline & & per cent & $c c$. & $c c$ & $c c$. & millions & $\begin{array}{l}\text { volumes } \\
\text { per cent }\end{array}$ & per cent \\
\hline 1 & $\mathrm{~F}$ & +55 & 3730 & 81.0 & 2590 & 4.22 & 17.3 & 37.5 \\
\hline 2 & $\mathrm{~F}$ & +31 & 3315 & 73.0 & 2240 & 4.47 & 15.6 & 35.0 \\
\hline 3 & $\mathrm{~F}$ & +51 & 3610 & 58.2 & 2099 & 4.93 & 20.9 & 43.5 \\
\hline 4 & $\mathrm{~F}$ & +34 & 5120 & 76.4 & 2910 & 4.71 & 20.0 & 44.0 \\
\hline 5 & $\mathrm{~F}$ & +73 & 4041 & 74.1 & 2574 & 5.00 & 19.1 & 43.0 \\
\hline 6 & $\mathrm{~F}$ & +33 & 4780 & 74.0 & 2860 & & 18.2 & \\
\hline 7 & $\mathrm{~F}$ & +30 & 4880 & 69.0 & 2638 & 5.13 & 19.8 & 44.0 \\
\hline 8 & $\mathrm{~F}$ & +47 & 3100 & 62.4 & 2095 & 4.51 & 14.7 & \\
\hline 9 & $\mathrm{~F}$ & +54 & 4552 & 86.3 & 2958 & 5.28 & 20.1 & \\
\hline 10 & $\mathrm{~F}$ & +68 & 3325 & 62.6 & 2190 & 5.28 & 18.5 & 43.2 \\
\hline 11 & $\mathrm{~F}$ & +43 & 3250 & 69.2 & 2258 & 4.38 & 14.7 & 34.8 \\
\hline 12 & $\mathrm{~F}$ & +74 & 4500 & 95.0 & 3100 & 4.44 & 12.8 & 34.8 \\
\hline 13 & M & +50 & 5100 & 81.0 & 2930 & & 18.4 & 43.7 \\
\hline 14 & $F$ & +40 & 3285 & 78.0 & 2570 & 4.68 & 16.2 & \\
\hline 15 & $\mathrm{~F}$ & +23 & 3610 & 60.6 & 2175 & 4.33 & 17.5 & \\
\hline 16 & $\mathrm{~F}$ & +48 & 3930 & 84.4 & 2730 & 4.31 & 16.5 & 37.8 \\
\hline 17 & M & +70 & 4170 & 91.2 & 2725 & 4.87 & 16.3 & 47.4 \\
\hline 18 & M & +61 & 5610 & 115.2 & 3635 & 5.20 & 18.5 & \\
\hline 19 & $\mathrm{~F}$ & +109 & 3965 & 82.6 & 2680 & 5.09 & 16.5 & 40.0 \\
\hline 20 & $\mathrm{~F}$ & +80 & 3120 & 72.4 & 2200 & 5.01 & 17.1 & 39.5 \\
\hline 21 & $\mathrm{~F}$ & +34 & 5390 & 88.0 & 2950 & 5.14 & 20.6 & 47.0 \\
\hline \multicolumn{2}{|c|}{ Average } & +53 & 4113 & 77.8 & 2624 & 4.79 & 17.6 & 40.9 \\
\hline
\end{tabular}

These high values for the volume of blood in hyperthyroidism might have been argued to be only apparent since these patients had probably all lost weight and the circulatory volume relative to the body weight and the body surface would naturally be high. To settle this point it remained necessary to study these cases both during the course of the illness and after a cure was effected through partial removal of the diseased thyroid gland. This was possible in 15 patients in whom in addition to the initial determination subsequent examinations were carried out after the institution of treatment. The routine therapeutic procedure consisted of digitalization and administration of Lugol's 
solution, followed, at an opportune time, by subtotal thyroidectomy. After the operation the patients were symptomatically relieved and their basal metabolic rates practically all returned to the normal level. The time between the operation and the subsequent determination of blood volume varied from 10 days to 5 months, but in the majority of cases the interval was fairly short so that little difference, if any, existed between the patient's weight before and after the surgical procedure. The results are given in Table $3 .^{2}$ In Table 4 the percentage decrease of the metabolic rate after the operation is compared with the corresponding figure for the blood volume. It may be seen that these two run quite parallel with each other. Only in Case 14 does this parallelism not seem to exist and it is interesting to note that this is the only patient in the series who had a toxic adenoma. This patient did not appear ill; there was no tachycardia or cardiac enlargement and the only indication of disease was the elevated metabolism. Subtotal thyroidectomy was not performed for this patient. After the enucleation of the adenoma the metabolism fell but not the blood volume. In nearly all the cases, while the diminution of the blood volume following the operation was definite and far exceeded the maximal error of the experimental method, it was less striking than the decrease in metabolism. This is probably because metabolism permits a greater deviation from normal and because the change in blood volume is not the only circulatory adjustment in hyperthyroidism. As a rule the total blood volume and the volume relative to the body surface showed a percentage fall of approximately the same magnitude.

That the observed postoperative change in the blood did not represent the immediate effect of the surgical interference was clearly shown in Case 9. This patient was followed for nearly two years after her operation. Her blood volume throughout this period remainedpractically the same and was always considerably lower than before the subtotal thyroidectomy.

Iodine in the form of Lugol's solution efficiently lowered the basal metabolism in all the cases. Of the five patients studied after the administration of this drug four showed a decisive drop in blood volume

2 The first seven cases were studied through the kindness of Dr. G. A. Harrop, Jr., in the Johns Hopkins Medical Clinic, to whom the author wishes to express his appreciation. 


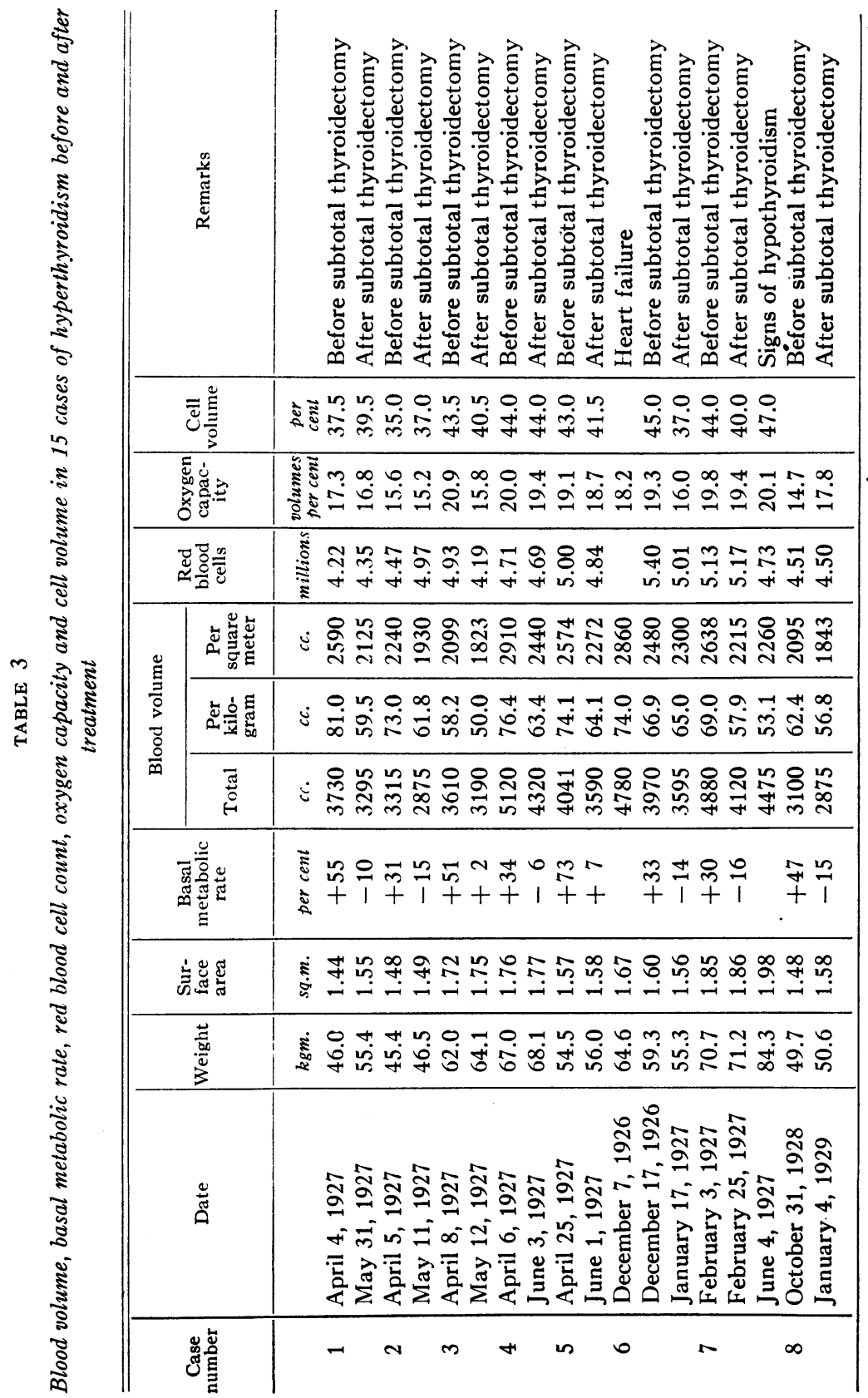




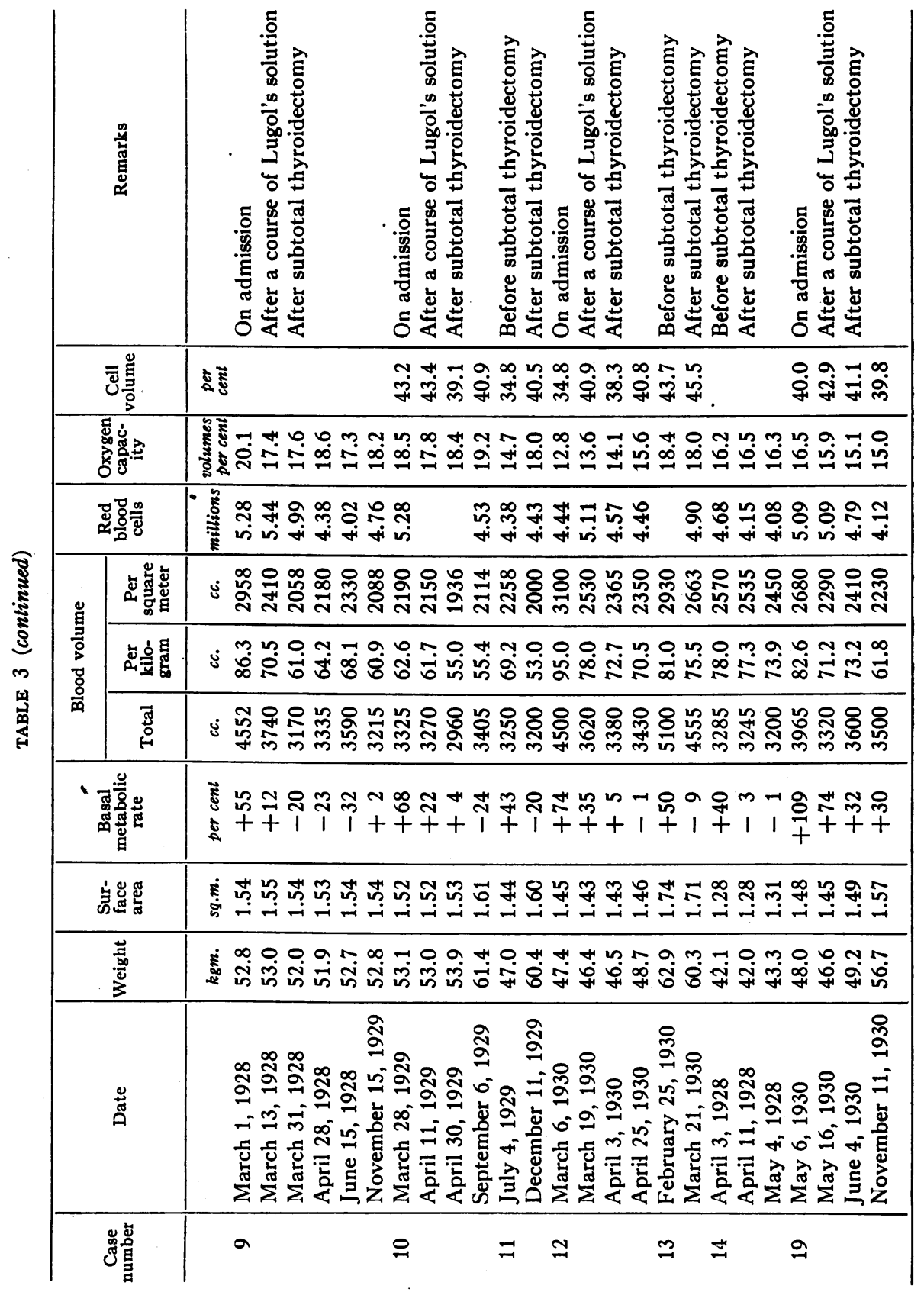




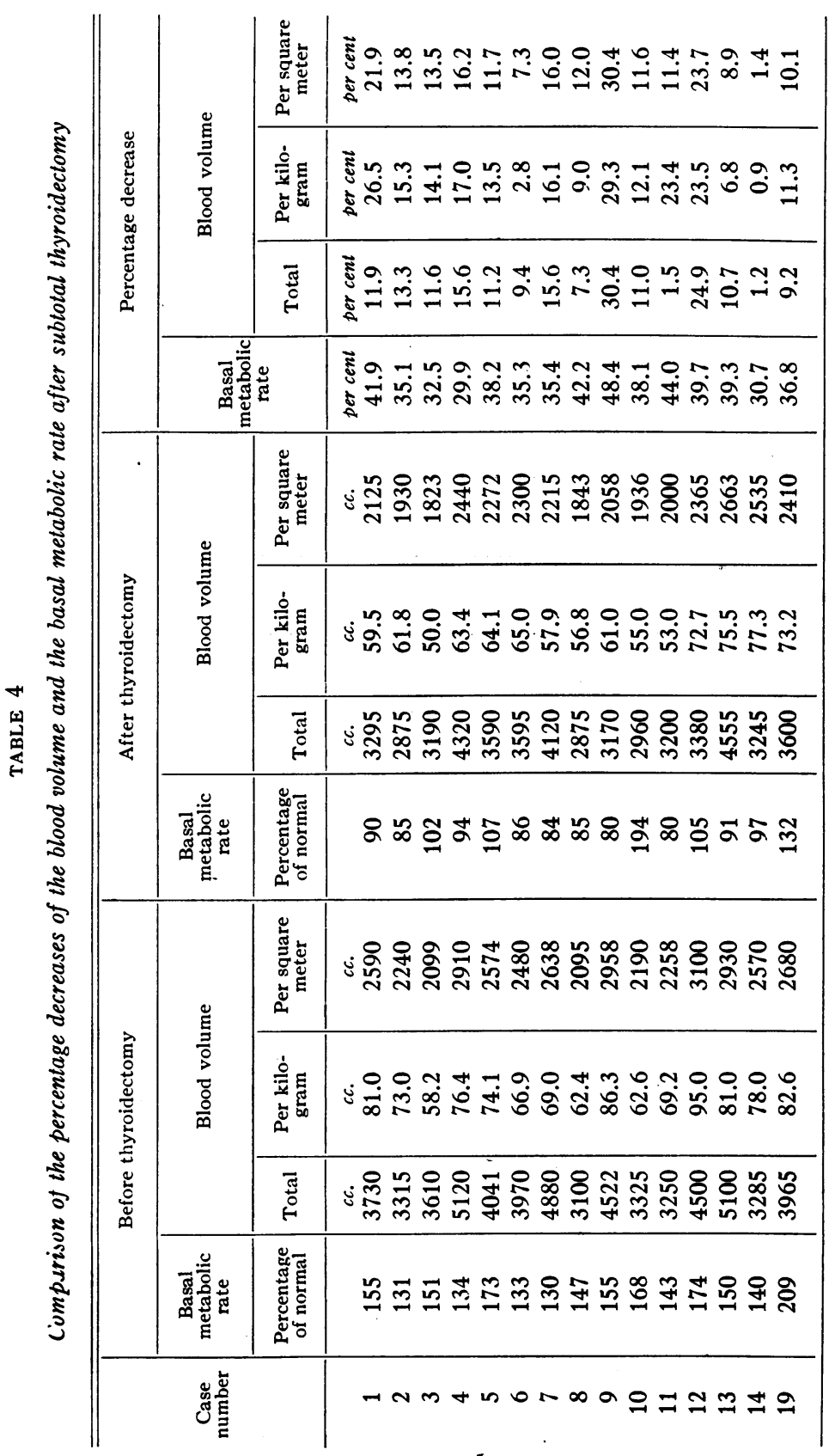


along with the fall in metabolism. Following the partial removal of the thyroid gland there was in these patients a further decrease in the circulating blood.

\section{DISCUSSION}

The results given above clearly illustrate the adjustment of circulation in time of need. The elevation of metabolism in thyrotoxicosis places the patient at rest on a physiological level with a normal person during physical exertion. The increased demand for oxygen necessitates an increase in the circulation. The relation between the basal metabolism and the pulse rate is a well recognized fact in Graves' disease (18). The behavior of the cardiac output and the blood flow under the same circumstances has already been referred to. Barcroft's classical experiment (19) on the exteriorized spleen has shown that there is an outpouring of blood from this important reservoir during exercise. This sudden addition of blood to the systemic circulation must mean a considerable increase in its volume. As hyperthyroidism and physical exercise are closely analogous, the increase in the circulating volume in these two conditions may be looked upon as the same physiological and compensatory mechanism. The extra load thus imposed on the heart may well serve to throw light upon the pathogenesis of heart failure in thyroid disease. To push the analogy further there seems little distinction, etiologically, between the thyroid heart and the heart disease occasionally observed among the athletes, the difference being that in the case of the former the insult to the cardiovascular system is constantly operative and the damage becomes, therefore, severer. The lowering of metabolism after partial thyroidectomy means a decrease in oxygen requirement and consequently there is a return of the blood to its normal volume. Similarly in hypothyroidism, in which an abnormally low metabolism prevails, the opposite change in blood volume would be expected to take place. This is actually the case, as was demonstrated by Thompson (20). This author employed the dye method for the determination of blood volume. He was able to increase the plasma volume of his patients, frequently to the extent of 25 per cent, by the administration of thyroxin or thyroid extract. On omission of the glandular therapy the plasma volume invariably decreased again. Table 5 records the findings by the carbon monoxide method for blood volume in a case of 


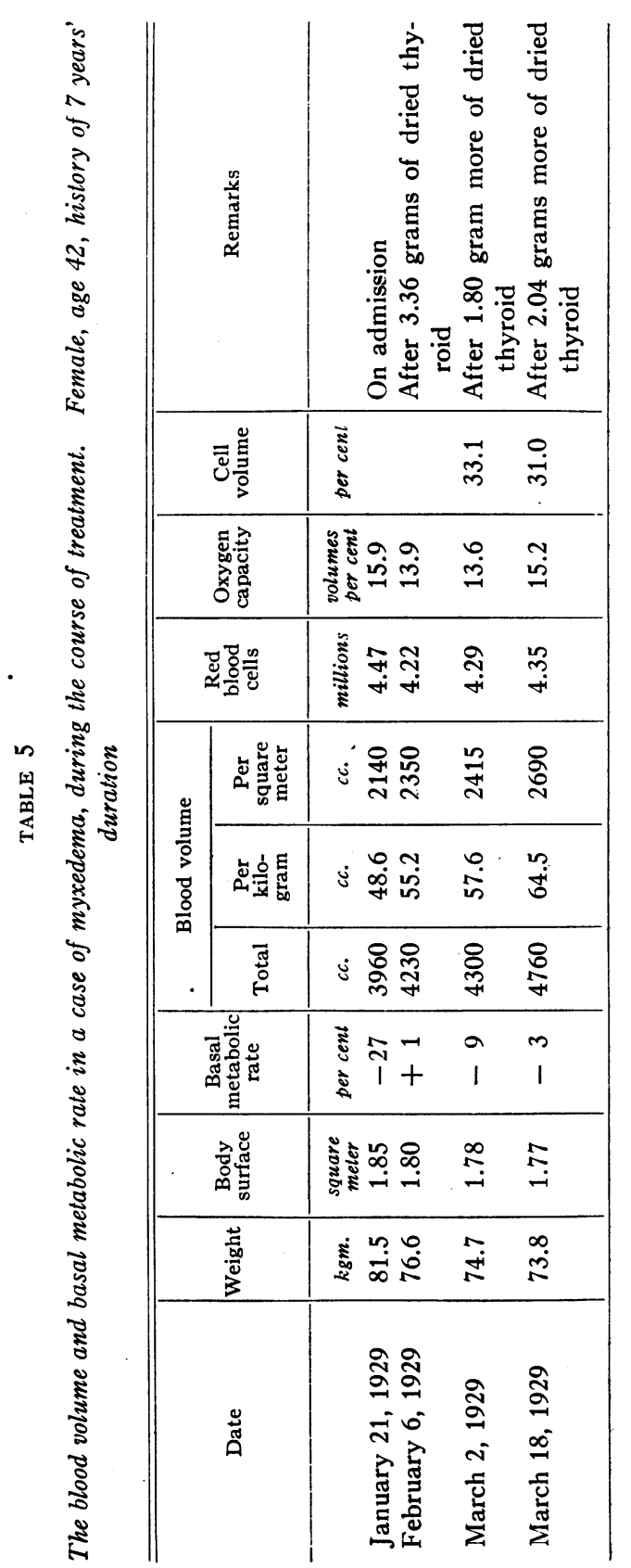


myxedema; these are entirely in accord with Thompson's observations.

We may now turn to consider the question from another standpoint, namely, that of hemodynamics. In hyperthyroidism, particularly in exophthalmic goiter, the blood supply of the thyroid gland is considerably increased. The pulsation and bruit often elicited over the diseased gland indicate a marked increment of its vascularity. The neck veins and the carotid arteries are frequently dilated. There is thus a wide capillary bed in the neck which may short circuit a large portion of the blood and may bear a close resemblance to an arteriovenous fistula. The similarity between the two conditions may be exemplified further. In hyperthyroidism a high pulse pressure is quite a constant feature. There is flushing of the skin from which may be inferred a diminution of the peripheral resistance. There seems an increase in the vascular bed generally as well as over the thyroid gland. This is precisely what occurs in the arteriovenous fistula. Holman (21) in a series of experiments has shown that in the case of an arteriovenous fistula, the gradually increasing dilatation of the vascular bed is compensated by a corresponding increase in the blood volume and that this volume change may be easily rectified by either temporary or permanent closure of the fistula. In the light of Holman's findings it seems difficult to expect the circulatory volume to behave otherwise in exophthalmic goiter. The partial excision of the hypertrophied thyroid may be rightly compared with the closing of the arteriovenous fistula. In this connection it is interesting to note that in Case 14 of the series here reported, (the case of toxic adenoma), in which no profound vascular change of the thyroid gland was present the initial blood volume did not appear excessively high nor was a postoperative reduction observed.

From these theoretical considerations and the actual experimental data it seems highly plausible to explain the pathologic physiology of the circulatory system in thyrotoxicosis on the following basis. The elevated metabolism means increased oxygen consumption and increased transportation of metabolites. This increased demand must be met by some adjustment on the part of the circulating medium. Such an adjustment is accomplished by an elevation of the pulse rate, augmentation of the cardiac output, acceleration of the blood flow, 
enlargement of the vascular bed and by increase of the blood volume. The great vascularity of the diseased thyroid contributes to aggravate all these changes. The resulting extra load on and insult to the heart must be considerable and, when long continued, must eventually produce fatigue and failure. It is thus not necessary to assume any direct toxic action of the thyroid hormone on the heart in order to seek an understanding of the familiar cardiovascular disturbance in hyperthyroidism.

\section{SUMMARY}

The circulating blood volume of 21 cases of hyperthyroidism was determined by the carbon monoxide method and was found to be much higher than the average normal volume. Of the 15 cases in which subsequent determinations were possible following subtotal thyroidectomy all but one (a case of toxic adenoma) showed a definite reduction of the blood volume after the operation. Five cases were studied after the administration of Lugol's solution. This treatment alone had an appreciable effect in decreasing the blood volume along with the fall in the basal metabolic rate.

The significance of these findings and their bearing on the pathogenesis of the cardiovascular disturbance in thyroid disease are discussed.

\section{BIBLIOGRAPHY}

1. Goodpasture, Ernest W., J. Am. Med. Assoc., 1921, lxxvi, 1545. Myocardial Necrosis in Hyperthyroidism.

2. Goodpasture, Ernest W., J. Exp. Med., 1921, xxxiv, 407. The Influence of Thyroid Products on the Production of Myocardial Necrosis.

3. Willius, F. A., Boothby, W. M., and Wilson, L. B., Med. Clin. North America, 1923, vii, 189. The Heart in Exophthalmic Goiter and Adenoma with Hyperthyroidism.

4. Lahey, F. H., Ann. Surg., 1929, xc, 750. End-Results in Thyrocardiacs.

5. Thomas, H. M., Jr., Bull. Johns Hopkins Hosp., 1930, xlvii, 1. Thyroid Heart: a Transitory Condition.

6. Plesch, J., Ztschr. f. exper. Path. u. Therap., 1909, vi, 380 . Hämodynamische Studien.

7. Stewart, G. N., Harvey Lect., 1912, viii, 86. Studies on the Circulation in Man: The Blood Flow in the Hands and Feet in Normal and Pathological Cases.

8. Davies, H. W., Meakins, J., and Sands, J., Heart, 1924, xi, 299. The Influence of Circulatory Disturbances on the Gaseous Exchange of 
the Blood. V. The Blood Gases and Circulation Rate in Hyperthyroidism.

9. Rabinowitch, I. M., and Bazin, E. V., Arch. Int. Med., 1926, xxxviii, 566. The Output of the Heart per Beat in Hyperthyroidism.

10. Blalock, A., and Harrison, T. R., Surg., Gyn., and Obst., 1927, xliv, 617. The Regulation of the Circulation. IV. The Effects of Thyroidectomy and Thyroid Feeding on the Cardiac Output.

11. Burwell, C. S., Smith, W. C., and Neighbors, D., Am. J. Med. Sci., 1929, clxxviii, 157. The Output of the Heart in Thyrotoxicosis.

12. Fullerton, C. W., and Harrop, G. A., Jr., Bull. Johns Hopkins Hosp., 1930, xlvi, 203. The Cardiac Output in Hyperthyroidism.

13. Blumgart, H. L., Gargill, S. L., and Gilligan, D. R., J. Clin. Invest., 1930, ix, 69. Studies on the Velocity of Blood Flow. XIII. The Circulatory Response to Thyrotoxicosis.

14. Blotner, H., Fitz, R., and Murphy, W. P., J. Clin. Invest., (Proceedings), 1928, vi, 4. The Effect of Hyperthyroidism on the Total Blood Count.

15. Chang, H. C., and Harrop, G. A., Jr., J. Clin. Invest., 1928, v, 393. The Determination of the Circulating Blood Volume with Carbon Monoxide.

16. Lindhard, J., Am. J. Physiol., 1926, lxxvii, 669. A Dye-Method for Determining the Blood Volume in Man.

17. Plummer, W. A., Collected Papers of the Mayo Clinic, 1918, x, 359. The Blood Picture in Exophthalmic Goiter.

18. Minot, G. R., and Means, J. H., Arch. Int. Med., 1924, xxxiii, 576. The Metabolism-Pulse Ratio in Exophthalmic Goiter and in Leukemia.

19. Barcroft, J., and Stephen, J. G., J. Physiol., 1927-28, lxiv, 1. Observation upon the Size of the Spleen.

20. Thompson, W. O., J. Clin. Invest., 1925-26, ii, 477. Studies in Blood Volume. I. The Blood Volume in Myxedema, with a Comparison of Plasma Volume Changes in Myxedema and Cardiac Edema.

21. Holman, Emile, Arch. Surg., 1924, ix, 822. Experimental Studies in Arteriovenous Fistulas: I. Blood Volume Variations. 